\title{
THE INFLUENCE OF CHECK DAMS ON FLUVIAL PROCESSES AND RIPARIAN VEGETATION IN MOUNTAIN REACHES OF TORRENTS
}

\author{
Giuseppe Bombino, Vincenzo Tamburino, Demetrio Antonio Zema, Santo Marcello Zimbone
}

\section{Introduction}

Within the active channel fluvial processes induce complex effects on the development and organisation of riparian vegetation [Gurnell 1995; Hupp 2007]; on the other hand, the physical role of vegetation in influencing channel forms and dynamics [Gurnell 2002, 2006; Corenblit 2007; Malkinson 2007] is well known.

Particularly in mountain streams these interactions between hydrogeomorphological and ecological processes can be strongly impacted by engineering control works [Nakamura 2000; Lenzi 2002; Shafroth 2002; Petts 2005]. The installation of check dams, usually aimed at slowing water and sediment movements along stream channels through the decrease of the longitudinal slope towards the equilibrium conditions, can have important local effects on riparian vegetation and channel hydrogeomorphology, which in aggregate could have an important influence on stream systems.

For this purpose, we recently developed methods for investigating impacts of check dams [Bombino 2003, 2006] and embankments [Bombino 2007a] on riparian vegetation. We tested these methods on some "fiumaras" (ephemeral river systems typical of the Mediterranean environment) in semi-arid climatic conditions. The methods arranged within these studies were purposed at the quantitative evaluation of the direct local effects induced by torrent control works on riparian vegetation and clear influences of both check dams [Bombino 2006, 2007b, 2008a, 2009b, 2009a, 2009b] and embankments [Bombino 2007a] on coverage, development, species richness and biodiversity of

Paper received 25.01.2010; accepted 19.08.2010

Mediterranean University of Reggio Calabria, Department of Agro-forest and Environmental Science and Technology, Feo di Vito, I-89122 Reggio Calabria (Italy), tel. +39 0965 801282, fax +39 0965 312681, e-mail giuseppe.bombino@unirc.it.

The contribution of the authors to this paper can be considered equivalent. riparian complexes were demonstrated.

Recently, in order to better understand the influence of check dams on both channel forms (due to the particularly harsh conditions for riparian vegetation and the limited space for channel adjustment shown in steep headwater reaches) and sediment calibre (and consequently on the moisture retention capacity of the river bed, which has important impacts on vegetation development in semi-arid environments, particularly in headwater reaches), we have also investigated the active channel morphology [Bombino 2009a, 2009b] and the grain size characteristics of river bed material [Bombino 2008a] around check dams.

With respect to the previous investigations, the present analysis is extended to implications of check dam actions on water stream characteristics. The integration of geomorphological and granulometric aspects with those related to river hydraulics provides a suitable and systematic database, allowing, also through the application of techniques of multivariate statistic analysis, a better comprehension of the ecological response of riparian vegetation (in terms of structure and development) to the effects locally induced by hydrogeomorphological processes in proximity of check dams located in mountain reaches of four Calabrian torrents.

\section{Materials and methods}

\subsection{Study catchments}

The present investigation has been carried out in four headwater (mountain) reaches of the Calabrian fiumaras Allaro ("A"), Torbido di Gioiosa ("TG"), Sant'Agata ("SA") and Gallico ("G") (fig. 1).

The catchment areas of the four fiumaras vary from 56 ("G") to 161 ("TG") $\mathrm{km}^{2}$ and the main stream lengths vary from 17 ("TG") to 26 (“G”) km. They rise at over $1200 \mathrm{~m}$ above sea level, flow through deep narrow valleys (cross section width ranging from 11 to $24 \mathrm{~m}$ ) in their headwaters (mountain reaches) and wider floodplains downstream (valley reaches), discharging into the Ionian ("A", "TG" 
and "SA") or Thyrrenian sea ("G").

The four mountain reaches taken into account, mainly covered by riparian woodland of alders and poplars (belonging to the associations of Alnetum glutinoso-cordateae and Populetalia albae respectively), have been modified through the installation of several control structures. These headwaters, 3.7 ("TG") to 7 ("SA") km long, are characterised by steep thalwegs (mean slope equal to $9 \div 11 \%$ with subreaches getting 20\%) and high sediment transport capacity, with a median particle size of bed material $\left(\mathrm{D}_{50}\right)$ typically 80 to $90 \mathrm{~mm}$. Although the coastal zones of the study catchments have a Mediterranean climate, in the headwaters winters become very cold and summers are cool and the land cover is predominantly forest (mainly Fagus sylvatica L., Pinus nigra ssp. Laricio var. calabrica and Abies alba Mill.) and shrub.

\subsection{Survey and analysis methods}

Within each catchment, five check-dams, ranging in height from 3 to $4.5 \mathrm{~m}$ and located in headwater reaches that were considered 'homogenous' [Bombino 2006, 2007a] in terms of their climatic, geomor-

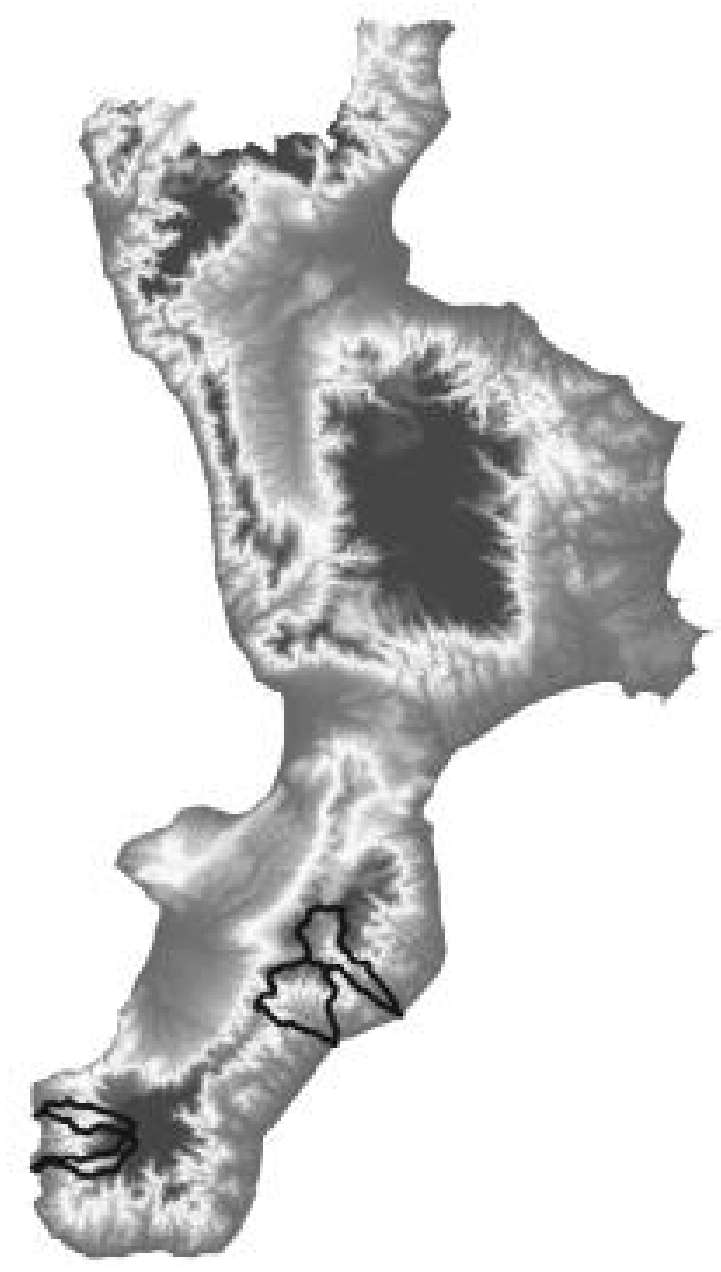

Fig. 1 - The locations of the four study catchments ("A" Allaro, "TG" Torbido di Gioiosa, "G" Gallico and "SA" Sant'Agata). phological and vegetation characteristics, were investigated. All were sufficiently old $(20 \div 25$ years $)$ for their impact on the river channel morphology and longitudinal slope (with respect to 'ante operam' conditions) as well as riparian vegetation to be fully developed. The four basins are of similar size with similar times of concentration and are located in close proximity within the same pluviometric region [Versace 1989] and so they experience similar sequences of high flows to shape their active channels. Coupling this with the fact that no extreme floods able to disrupt tree species or bury herbaceous and shrub layers (sufficiently to prevent their rapid re-establishment) have occurred in the last fifteen years, gives us confidence that it is valid to draw comparisons of morphological and vegetation properties of the active channel between catchments under the assumption that they are the product of a similar flow regime.

At each check dam, surveys were collected along three transects: upstream ("U"), downstream ("D") and intermediate ("I"). Upstream and downstream transects were located at the height of the check dam away from the dam. In the few cases where this criterion located the downstream site within the scour pool, it was relocated immediately downstream of the pool. The intermediate transects represented sites less disturbed by the presence of check dams, being located beyond the direct local influence - also in terms of local longitudinal slope - of these structures (between 30 and $70 \mathrm{~m}$ downstream from the dams, with shorter distances reflecting constraints resulting from close check dam spacing).

At each transect, several indicators were used to define the limits of the 'active channel', which in these ephemeral systems includes the contemporary riparian zone: a change in vegetation from riparian to terrestrial species (this was usually clearly defined by changes in the tree species); distinct breaks in slope and/or particle size; the position of scour or trash lines (fig. 2). The most consistent measure proved to be the change in vegetation species and this was refined using the other indicators wherever they were identified. Width and maximum active channel depth were then measured in correspondence of the free surface and the "width:depth ratio" (w/d) was calculated; w/d ratio $\left[\mathrm{m} \mathrm{m}^{-1}\right]$ was therefore considered as a synthetic shape parameter, indicative of the channel cross section morphology.

The hydraulic characteristics of the active river channels were represented by the specific discharge index (or discharge per unit width required to fill the active channel cross profile) $\mathrm{q}=\mathrm{Q} / \overline{\mathrm{w}}$, where $\overline{\mathrm{w}}$ is the 'mean' width of the transect, calculated as the ratio between the cross-sectional area and its depth d; $\overline{\mathrm{W}}$ varies from " $\mathrm{w}$ " for a rectangular cross section (typical of upstream transects) to "w/2" for a V-shaped channel (typical of downstream transects) with intermediate transects showing values in this range. The specific discharge $\mathrm{q}\left[\mathrm{m}^{3} \mathrm{~s}^{-1} \mathrm{~m}^{-1}\right]$ was calculated using the Manning's formula from field estimates of 


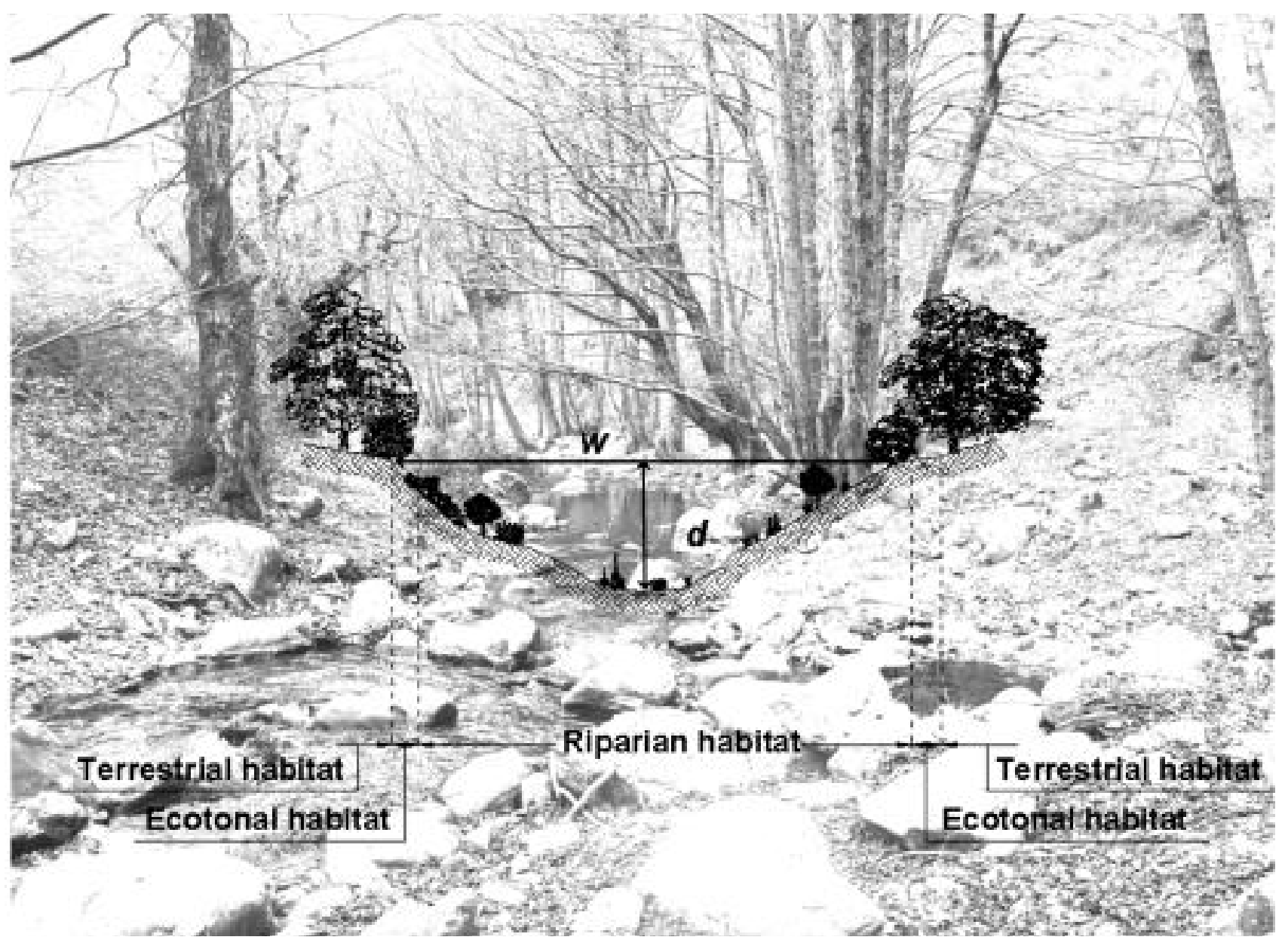

Fig. 2 - Schematic cross section of a typical transect in the study mountain reaches of the torrents A, TG, SA and G.

flow resistance, channel cross-profile (by w and d values) and longitudinal slope. The evaluation of $q$ has been operated by such hydraulic approach, given the direct dependence of discharge on the local longitudinal slope (remarkably different among homogenous groups of transects) expressed by Manning's formula. The $\mathrm{q}$ values calculated as above are very close (with a maximum deviation of $10 \div 12 \%$ ) to discharges of recurrence time of $1.5 \div 2$ years evaluated for the studied watersheds, responsible for cross section modeling [Leopold 1964; Gregory 1973; Richards 1982].

Within the active channel the surface and subsurface sediment calibre was investigated. The surface bed material was sampled in situ every $50 \div 60 \mathrm{~cm}$ along each transect using a photographic technique [Adams 1979; Ibbeken 1986; Petts 2000]. The particle distribution was obtained for each sample using the intermediate B-axis; the median particle size of bed material $\left(\mathrm{D}_{50},[\mathrm{~mm}]\right)$ was estimated from the combined measured particles obtained within sample across each transect [Bombino 2008a].

Four, two and two sub-surface sediment samples (within each upstream, downstream and intermediate transect, respectively) were also taken at $0.30-\mathrm{m}$ depth, in which the main root zone of many riparian species develops. More samples were obtained from upstream sites because they tended to be wider than downstream and intermediate transects. In the laboratory, the finer sediment fraction (less than $0.25 \mathrm{~mm}$ ) was separated from the bulk sample by sieving and was expressed as the percentage of the finer sediment by weight. The average percentage of finer sediment (\%fines, [\%]) was calculated for each transect. We focused on the fine sediment fraction because of its importance for moisture retention [Hillel 1982] within the root zone of plants in these ephemerally-flowing systems. Detailed information about sediment analysis can be found in previous works [Bombino 2008a].

Information was also collected on the floristic composition, ecological characteristics and spatial distribution of plant groups within the active channel at each of the transects using methods described by Bombino [2003, 2006]. Five synthetic parameters explaining these vegetation characteristics were estimated for each transect: the Global Canopy Cover (GCC, [\%]) and its Coefficient of Variation $\left(\mathrm{CV}_{\mathrm{GCC}},[\%]\right)$, the Weighted Canopy Height (WCH, [m]) and its Coefficient of Variation $\left(\mathrm{CV}_{\mathrm{WCH}},[\%]\right)$ as well as the Number of Species (Ns, [-]). The global canopy cover (GCC) is the sum of the \% cover of the herbaceous, shrub and tree layers multiplied, respectively, by $1 / 6$, $2 / 6$ and $3 / 6$. GCC values fall in the range $0 \%$ to $100 \%$. For example, in a stand with high vertical complexity in which each layer covers $100 \%$, the 
GCC has a value of 100; whereas if herbaceous and shrub layers cover, respectively, 50 and $80 \%$ of the survey area and the tree layer is absent, GCC has a value of 35. The GCC and $\mathrm{CV}_{\mathrm{GCC}}$ (expressed as percent value) of a complete transect were calculated as the weighted average by area of the values from the six sample areas.

The weighted canopy height $(\mathrm{WCH})$ is defined as the sum of the products of the average height of the individual layers (herbaceous, shrub, tree) and the corresponding canopy cover. For example, in a stand with a high vertical complexity in which each layer covers $100 \%$ and average heights are, respectively, $0.3 \mathrm{~m}$ (herbaceous layer), $1.2 \mathrm{~m}$ (shrub layer) and $4.0 \mathrm{~m}$ (tree layer), the $\mathrm{WCH}$ has a value of $5.5 \mathrm{~m}$; but if herbaceous and shrub layers cover, respectively, $50 \%$ and the tree layer is absent, the $\mathrm{WCH}$ has a value of $0.75 \mathrm{~m}$.

The $\mathrm{WCH}$ and $\mathrm{CV}_{\mathrm{WCH}}$ (expressed as percent value) representative of a complete transect were calculated as the weighted average by area of the values from the six sample areas.

Having established significant differences in each of the vegetation and physical properties of torrent channels around check dams, associations between $\mathrm{WCH}, \mathrm{GCC}$, their variability $\left(\mathrm{CV}_{\mathrm{GCC}}\right.$ and $\left.\mathrm{CV}_{\mathrm{WCH}}\right)$, Ns and surface $\left(D_{50}\right)$, subsurface (\% fines), specific discharge (q) and width:depth ratio (w/d) were explored using the Principal Components Analysis (PCA), a multivariate statistical technique, developed by Pearson [1901] and modified by Hoteling [1933], whose aim is the reduction of the dimensionality of a data set consisting of a large number of correlated variables, while retaining as much as possible of the variance within the data set, in order to identify new meaningful underlying variables [Sharma 1996].

The average transect values of each of these properties for the upstream, downstream and intermediate sites was analysed using the PCA based upon a Spearman rank correlation matrix. Finally, the degree to which relationships between the vegetation and physical properties were also affected by the presence of check dams were explored using the regression analysis. Linear regression models were estimated between four vegetation properties (dependent variables: GCC, $\mathrm{WCH}, \mathrm{CV}_{\mathrm{GCC}}$ and $\mathrm{CV}_{\mathrm{WCH}}$ ) and the two physical properties (independent variables: $\mathrm{q}$ and $\mathrm{w} / \mathrm{d}$ ).

Statistical and regression analyses were performed using XLSTAT ${ }^{\circledR}$ release 2009 and Microsoft Excel ${ }^{\circledR}$.

\section{Results and discussion}

\subsection{Variations in physical and vegetation properties of torrent channels around check dams}

In transects located upstream of check dams larger values of w/d ratios $\left(9.2 \div 34.7 \mathrm{~m}^{1} \mathrm{~m}^{-1}\right)$ and lower specific discharge $\left(1.3 \div 6.1 \mathrm{~m}^{3} \mathrm{~s}^{-1} \mathrm{~m}^{-1}\right)$ were recorded in comparison with intermediate sites, $\left(1.9 \div 15.1 \mathrm{~m}^{1} \mathrm{~m}^{-1}\right.$ and $2.4 \div 10.0 \mathrm{~m}^{3} \mathrm{~s}^{-1} \mathrm{~m}^{-1}$ for $\mathrm{w} / \mathrm{d}$ and $\mathrm{q}$ respectively). In contrast, smaller values of w/d and higher $q$ were surveyed in downstream sites $\left(1.1 \div 9.7 \mathrm{~m}^{1} \mathrm{~m}^{-1}\right.$ and $6.4 \div 16.1 \mathrm{~m}^{3} \mathrm{~s}^{-1} \mathrm{~m}^{-1}$ ) (Fig. 3). As expected, there was a remarkable decrease in the median particle size $\left(D_{50}\right)$ of bed material, in correspondence of a decrease in channel gradient, between upstream $(18 \div 38 \mathrm{~mm})$ and

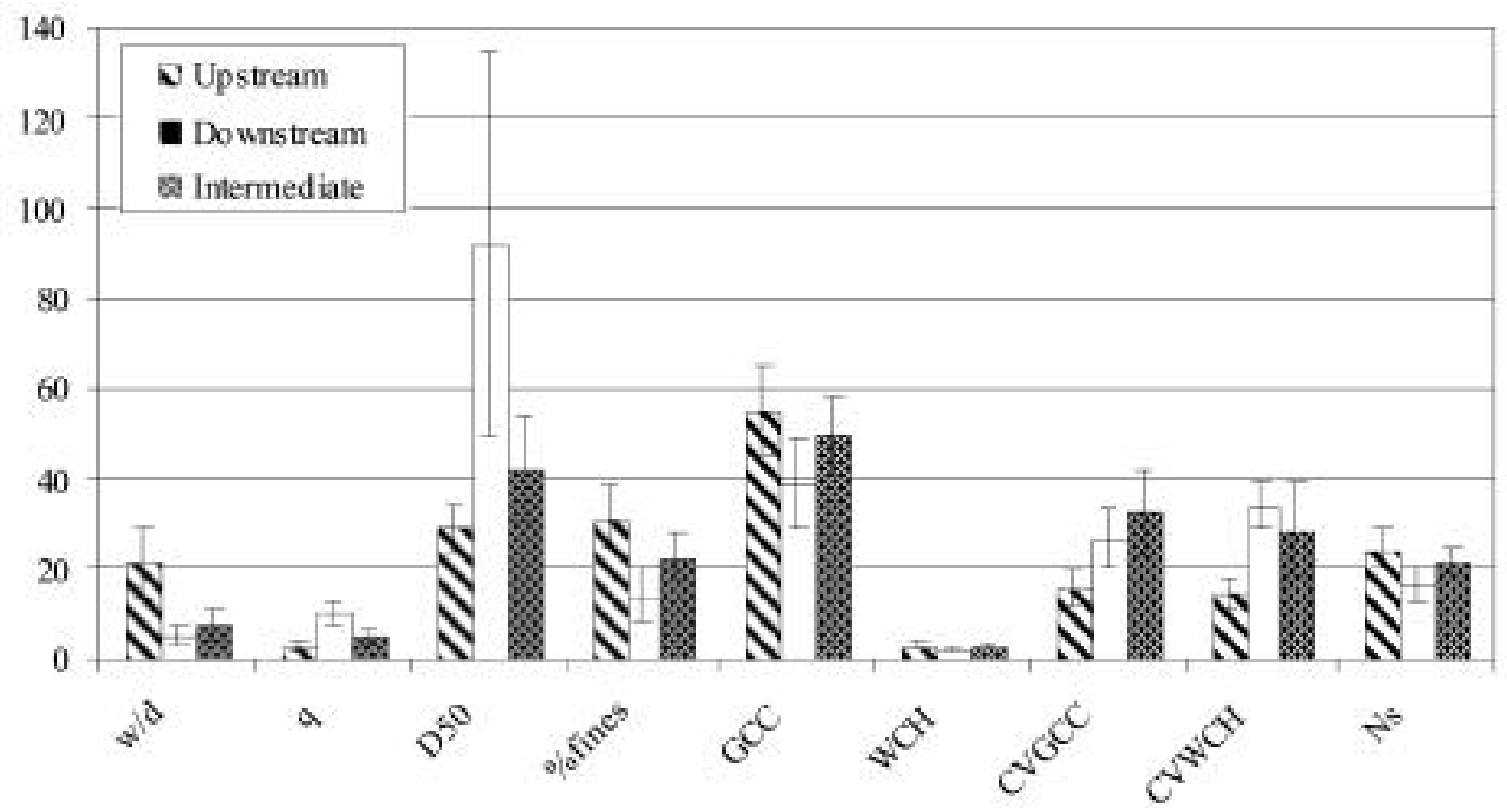

Fig. 3 - Mean and standard deviation of hydrogeomorphological (w/d $\left[\mathrm{m} \mathrm{m}^{-1}\right], \mathrm{q}\left[\mathrm{m}^{3} \mathrm{~s}^{-1} \mathrm{~m}^{-1}\right], \mathrm{D}_{50}$ [mm] and \% fines [\%]) and vegetation synthetic parameters $\left(\mathrm{GCC}[\%], \mathrm{WCH}[\mathrm{m}], \mathrm{CV}_{\mathrm{GCC}}[\%], \mathrm{CV}_{\mathrm{WCH}}[\%]\right.$ and $\left.\mathrm{Ns}[-]\right)$ in upstream, downstream and intermediate transects around the 20 check dams of the study mountain reaches in the torrents A, TG, SA and G. 
downstream $(21 \div 201 \mathrm{~mm})$ transects and a significant increase in the weight percentage of finer sediment in the subsurface (\%fines) from upstream $(21 \div 42 \%)$ through intermediate $(15 \div 31 \%)$ to downstream sites $(5 \div 23 \%)$ (fig. 3 ). These strong contrasts in both sediment characteristics between all transect locations extend the rather weaker, restricted findings from our previous pilot study of three sites on the Sant'Agata torrent [Bombino 2008a].

Substantial changes in the riparian vegetation around the control works were also evident from the field surveys and the consequential data processing. Riparian vegetation was found to be more extensive and more developed in the upstream transects (GCC ranges from 35 to $70 \%$; WCH from 2.1 to $4.5 \mathrm{~m}$ ) than at the intermediate sites (GCC 29-61\%, WCH 1.4-3.6 $\mathrm{m})$ with the reverse pattern in the downstream transects (GCC 15-53\%, WCH 0.6-3.2 m), as more clearly explained in the next section (fig. 3). There were also more species found upstream than in intermediate transects and more in intermediate than in downstream sites (fig. 3). The average increase in the values of the vegetation parameters at upstream in comparison with intermediate transects varied between the study torrents from $9.8 \%$ to $13.1 \%$ for $\mathrm{GCC}$, from $8.1 \%$ to $18.3 \%$ for $\mathrm{WCH}$ and from $15.2 \%$ and $20.5 \%$ for Ns. There was also a strong reduction in these parameters when average values for downstream transects were compared with intermediate sites across the four torrents (up to $-26 \%$ for GCC, $-49 \%$ for $\mathrm{WCH}$ and $-31.3 \%$ for Ns) (fig. 3).

In terms of transverse variability of vegetation coverage and structure (respectively linked to its distribution and development) along each of the survey transects (from the thalweg to the torrent banks), represented by the coefficients of variation of GCC and $\mathrm{WCH}$ between the six sample area surveys within each transect, overall lower values of $\mathrm{CV}_{\mathrm{GCC}}$ $(0.10 \div 0.23)$ and $\mathrm{CV}_{\mathrm{WCH}}(0.10 \div 0.20)$ were recorded in upstream transects in comparison with intermediate sites $\left(0.17 \div 0.49\right.$ for $\mathrm{CV}_{\mathrm{GCC}} ; 0.11 \div 0.46$ for $\left.\mathrm{CV}_{\mathrm{WCH}}\right)$, but contrasts between values at downstream and intermediate transects were small (fig. 3).

\subsection{Relationships between vegetation and physical properties of torrent channels around check dams}

The results of the analysis demonstrate clear and relevant contrasts in the morphological, hydraulic and sedimentary properties surveyed in the upstream, downstream and intermediate transects. These contrasts are reflected in differences in the number of species, cover and development of riparian vegetation growing within the active channel.

The Principal Components Analysis identified two new variables (Principal Components) that explained over $85 \%$ of the variance in the data set (fig. 4); just the PC1 (the first Principal Component) explains a variance equal to $75.3 \%$ of the total.

The very high positive loadings (indicating the extent to which the original variables are influential or important in forming the principal components) of $\mathrm{WCH}, \mathrm{GCC}$, w/d and \%fines on the one hand and of $\mathrm{CV}_{\mathrm{GCC}}, \mathrm{CV}_{\mathrm{WCH}}$ and $\mathrm{q}$ on the other hand on PC1 (fig. 4) highlight a strong association between groups of physical properties and vegetation of the whole transect; moreover, $\mathrm{CV}_{\mathrm{GCC}}, \mathrm{CV}_{\mathrm{WCH}}$ and $\mathrm{q}$ are inversely correlated to $\mathrm{WCH}, \mathrm{GCC}$, w/d and \%fines (coefficients of correlations between a couple of variables always higher than 0.63 , tab. 1). $\mathrm{D}_{50}$ and Ns had appreciable loadings on both PC1 and PC2 (the second Principal Component); between the hydrogeomorphological properties and vegetation parameters taken into account, $\mathrm{D}_{50}$ and Ns seem to have a lower influence on PC1 as well as the highest on PC2 (fig. 4).

$\mathrm{PC} 1$ defines a strong gradient from high values of $\mathrm{D}_{50}, \mathrm{q}, \mathrm{CV}_{\mathrm{GCC}}$ and $\mathrm{CV}_{\mathrm{WCH}}$ (negative loadings) to high values of \%fines, w/d, GCC, WCH and Ns (positive loadings) (fig. 4). Downstream, intermediate and upstream transects are arranged in a sequence along this gradient demonstrating a distinct contrast in all of the variables according to site location with respect to check dams with only a limited overlap between the three transect groups (upstream, downstream and intermediate) (fig. 5a).

Values of PC1 are linked to those original physical factors (see values of w:d ratio, $\mathrm{q}$ and \%fines) which,

\begin{tabular}{lccccccccc}
\hline Original variables & $\mathrm{w} / \mathrm{d}$ & $\mathrm{q}$ & $\mathrm{D}_{50}$ & \%fines & $\mathrm{GCC}$ & $\mathrm{WCH}$ & $\mathrm{CV}_{\mathrm{GCC}}$ & $\mathrm{CV}_{\mathrm{WCH}}$ & $\mathrm{Ns}$ \\
\hline $\mathrm{w} / \mathrm{d}$ & 1 & -0.88 & -0.71 & 0.87 & 0.82 & 0.84 & -0.88 & -0.94 & 0.55 \\
$\mathrm{q}$ & -0.88 & 1 & 0.75 & -0.81 & -0.83 & -0.82 & 0.68 & 0.84 & -0.64 \\
$\mathrm{D}_{50}$ & -0.71 & 0.75 & 1 & -0.74 & -0.59 & -0.61 & 0.48 & 0.65 & -0.72 \\
$\%$ fines & 0.87 & -0.81 & -0.74 & 1 & 0.79 & 0.78 & -0.67 & -0.84 & 0.61 \\
$\mathrm{GCC}$ & 0.82 & -0.83 & -0.59 & 0.79 & 1 & 0.92 & -0.63 & -0.76 & 0.45 \\
$\mathrm{WCH}$ & 0.84 & -0.82 & -0.61 & 0.78 & 0.92 & 1 & -0.67 & -0.79 & 0.45 \\
$\mathrm{CV}$ & -0.88 & 0.68 & 0.48 & -0.67 & -0.63 & -0.67 & 1 & 0.85 & -0.38 \\
$\mathrm{CV}_{\mathrm{WCC}}$ & -0.94 & 0.84 & 0.65 & -0.84 & -0.76 & -0.79 & 0.85 & 1 & -0.51 \\
$\mathrm{Ns}$ & 0.55 & -0.64 & -0.72 & 0.61 & 0.45 & 0.45 & -0.38 & -0.51 & 1 \\
\hline
\end{tabular}

TABLE 1 - Spearman rank correlation matrix between hydrogeomorphological and vegetation synthetic parameters (original variables of PCA) for whole transects around the 20 check dams of the study mountain reaches in torrents A, TG, SA and G. 


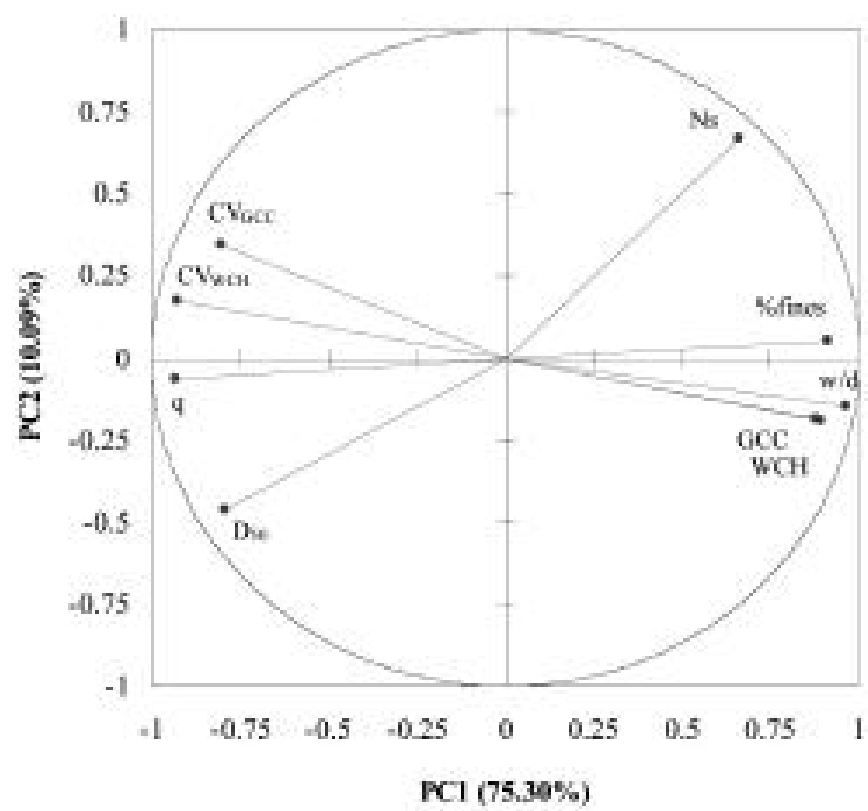

Fig. 4 - Loadings of original variables $\left(\mathrm{D}_{50}\right.$, \% fines, w/d, $\mathrm{q}, \mathrm{GCC}$, $\mathrm{WCH}, \mathrm{CV}_{\mathrm{GCC}}, \mathrm{CV}_{\mathrm{WCH}}$ and $\mathrm{Ns}$ ) on the first two principal components (PC1 and PC2) for whole transects around the 20 check dams of the study mountain reaches in torrents A, TG, SA and G. The percentage of the total variance explained by each component is indicated in the relevant axis label.

inducing better edaphic conditions within the active channel, encourage a greater coverage and development (as highlighted by the values of GCC and WCH) and transverse uniformity (see the lower values of
$\mathrm{CV}_{\mathrm{GCC}}, \mathrm{CV}_{\mathrm{WCH}}$ ) of riparian vegetation. This is clear in transects located upstream of check dams whose values (so called "scores") on PC1 are remarkably higher than other transects (fig. 5a).

PC2 shows a gradient from high values of $\mathrm{D}_{50}$ (negative loadings) to high values of Ns (positive loading) (fig. 4). PC2 seems to be more related to: i) the physical factors of active channel which show a lower incidence on vegetation properties (i.e. $\mathrm{D}_{50}$ ), as highlighted in previous investigations [Bombino $2008 \mathrm{a} ; 2009 \mathrm{a}$; ii) the vegetation properties (e.g. the species richness, expressed by the Ns) not linked to coverage and development (figure 4). Transects from the four study fiumaras overlap heavily, but are weakly arranged along this second gradient and, in particular, follow the alignment of the $\mathrm{D}_{50}$ and Ns variables, indicating that three fiumaras $(\mathrm{A}, \mathrm{TG}$ and $\mathrm{G})$ tend to have slightly more species and finer $\mathrm{D}_{50}$ than the fiumara Sant' Agata (fig. 5b).

Moreover, vegetation parameters (mainly GCC and $\mathrm{WCH})$ surveyed for the groups of transects are strongly correlated with the w/d ratio $(\mathrm{r}>0.82)$, $\mathrm{q}(\mathrm{r}<-$ $0.82)$ and \%fines $(r>0.78)$ parameters (tab. 1). It confirms that, in comparison with the torrent conditions ante operam: i) the widening of the cross section of the active channel, by assuring a greater availability of space within the transect, reduces the specific discharge and, as a consequence, the extirpation phenomena linked to the stream water; ii) the contemporary reduction of the local longitudinal slope encourages the deposition of fine sediment particles (and then

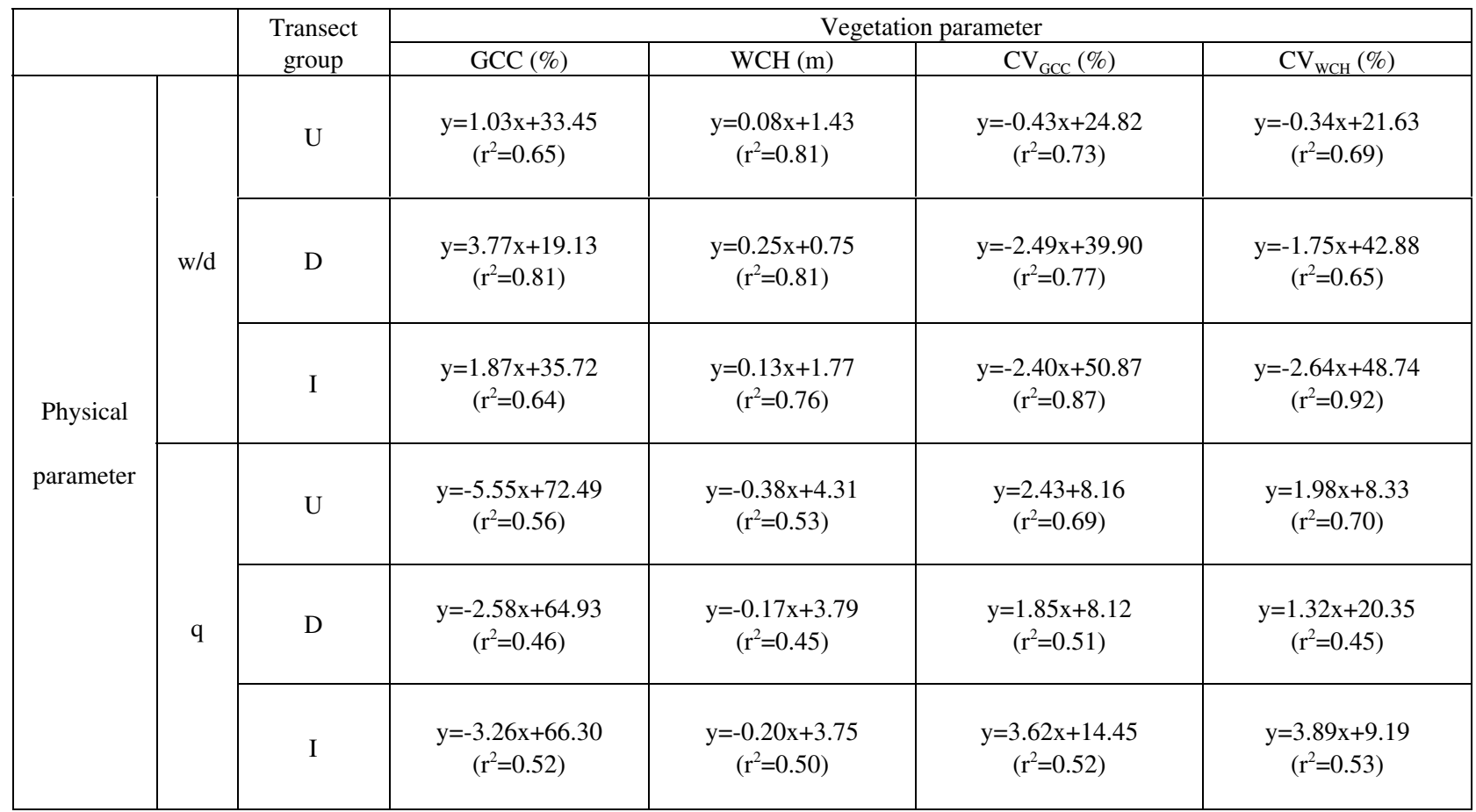

TABLE 2 - Linear regression equations $(y=m x+n)$ and related coefficients of determination $\mathrm{r}^{2}$ (in parentheses) between physical

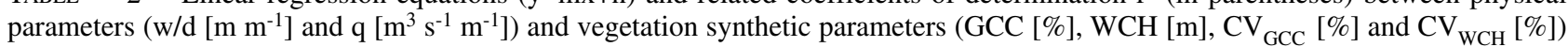
in upstream, downstream and intermediate transects around the 20 check dams of the study mountain reaches in torrents A, TG, SA and $\mathrm{G}$. 
higher water retention capacity). Such effects, together with the stabilization of hillslopes (which can be colonised by vegetation) in proximity of the channel, induced by the new longitudinal profile, improve the ecological conditions of the riparian habitat. Conversely, where the transects are narrowing (lower w/d, which means limited presence of fine sediment, and higher q, which induces intense bed shear stresses), the coverage and the development of riparian vegetation show a lower uniformity, as shown by the relevant negative (for w/d ratio and \%fines) or positive (for $\mathrm{q}$ ) correlations with CVs of GCC and WCH (tab. 1).

The regression analysis, applied to groups of transects (upstream, downstream and intermediate), show very different relationships between the vegetation properties (GCC, $\mathrm{WCH}$ and their $\mathrm{CVs}$ ) and w/d ratio in upstream transects than in downstream and intermediate sites (tab. 2). The higher extent and development (GCC and $\mathrm{WCH}$ ) of riparian vegetation in upstream transects is achieved within cross-profiles with a disproportionately large w/d and increase at a more gradual rate with increasing $w / d$ than in intermediate or downstream sites (fig. $6 \mathrm{a}$ and $6 \mathrm{~b}$ ). In these upstream transects, a higher w/d reduce the scouring and burying effects of high flows, allowing relatively long periods of low disturbance during which vegetation cover (GCC) and vertical development (WCH) can occur.

In addition, upstream transects display generally lower variation in vegetation properties $\left(\mathrm{CV}_{\mathrm{GCC}}\right.$ and $\mathrm{CV}_{\mathrm{WCH}}$ ) and this variation reduces more gradually with increases in channel w/d than in intermediate and
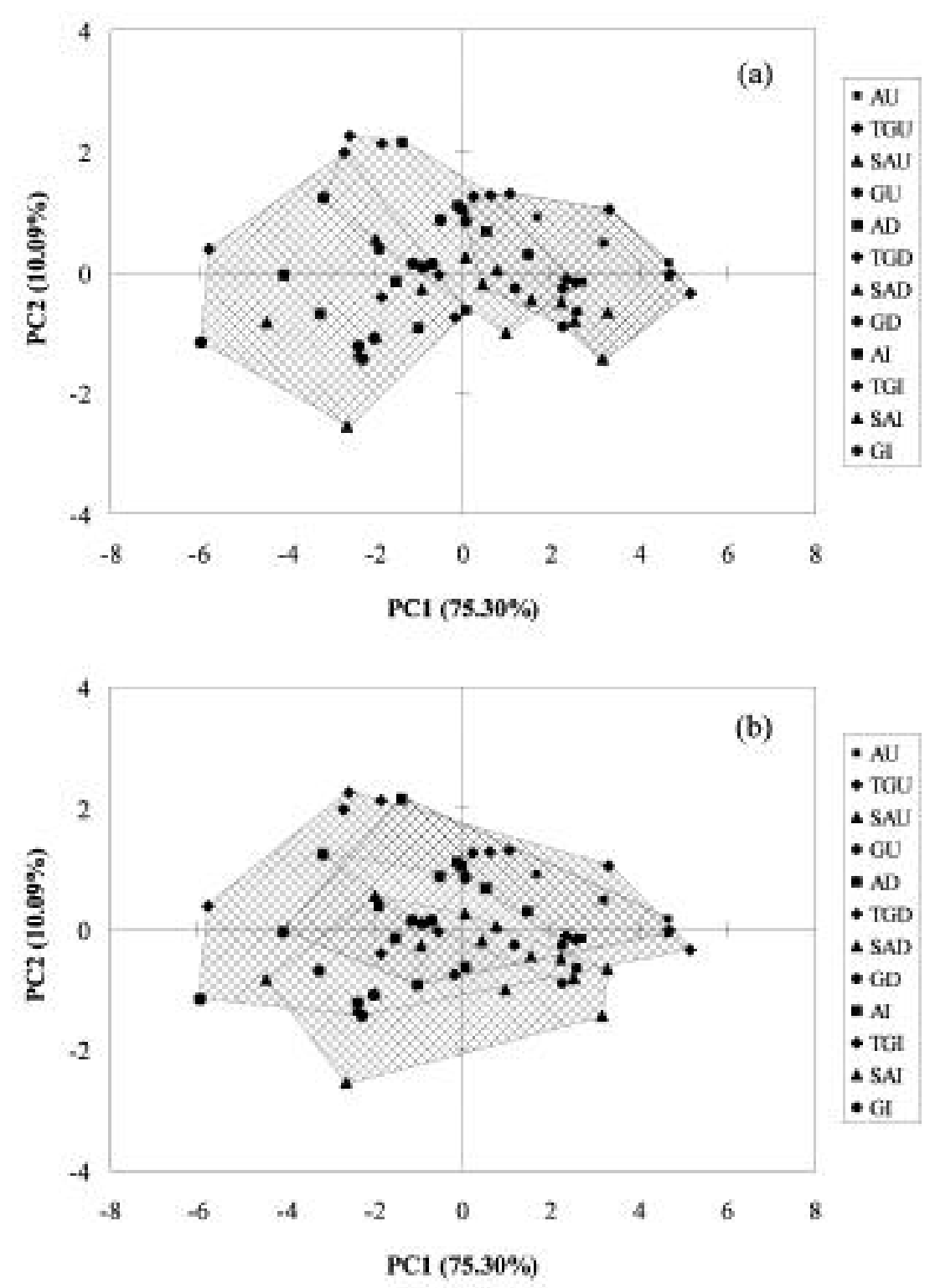

Fig. 5 - a, b Plot of transect scores on the first two principal components (PC1 and PC2) of an analysis of the physical and vegetation variables for whole transects around the 20 check dams of the study mountain reaches in torrents A, TG, SA and G. In both graphs, each transect is represented by a symbol indicating its position (U, D, I) and catchment (A, TG, SA, G).

In the upper graph the polygons mark the outer limits of the plotting positions of $\mathrm{U}, \mathrm{D}$ and I transects, whereas in the lower graph the polygons mark the outer limits of transects from each catchment. 
downstream transects (fig. 6c and 6d). Although there are remarkable differences in relationships between vegetation properties and w/d in intermediate and downstream transects, these differences are much smaller than those between both intermediate and downstream sites and the upstream transects [Bombino 2009a, 2009b].

Figures $6 \mathrm{a}, \mathrm{b}$ show that the slopes of regression lines between vegetation and physical properties for upstream transect groups are lower than those of downstream and intermediate groups. As a matter of fact, downstream of check dams (and less remarkably in I transects) an increase of w/d (and therefore a higher availability of space) within deeper and confined transects makes more appreciable the edaphic effects of the new ecological habitat. Similarly, as highlighted by Figures $6 c$, d, the same increase of the w/d ration make the riparian vegetation more uniform in the D and C transect, due the higher stability of the different vegetation layers (herbaceous, shrub and tree).

The relationships between the vegetation properties (GCC, WCH and their CVs) and the specific dis- charge q highlight a lower extent (GCC) and development $(\mathrm{WCH})$ of riparian vegetation within the active channel in downstream transects in comparison with upstream and intermediate sites (tab. 2), with vegetation development declining more rapidly with an increasing specific discharge in upstream transects than in intermediate and downstream sites (fig. 7a and 7b).

Variation in both extent $\left(\mathrm{CV}_{\mathrm{GCC}}\right)$ and development $\left(\mathrm{CV}_{\mathrm{WCH}}\right)$ of vegetation is lower in upstream than in downstream and intermediate transects, but whereas the variability in extent of vegetation increases at the same rate with increasing specific discharge regardless of transect subgroup, the variability in vegetation development increases less rapidly with specific discharge in upstream and downstream sites than in intermediate transects (fig. 7c and 7d).

The number of species Ns differ between upstream, intermediate and downstream transects regardless of the form or specific discharge capacity of the active channel (data not shown), indicating an increase in the number of species colonising the active channel in upstream sites above background levels (indicated by intermediate transects).
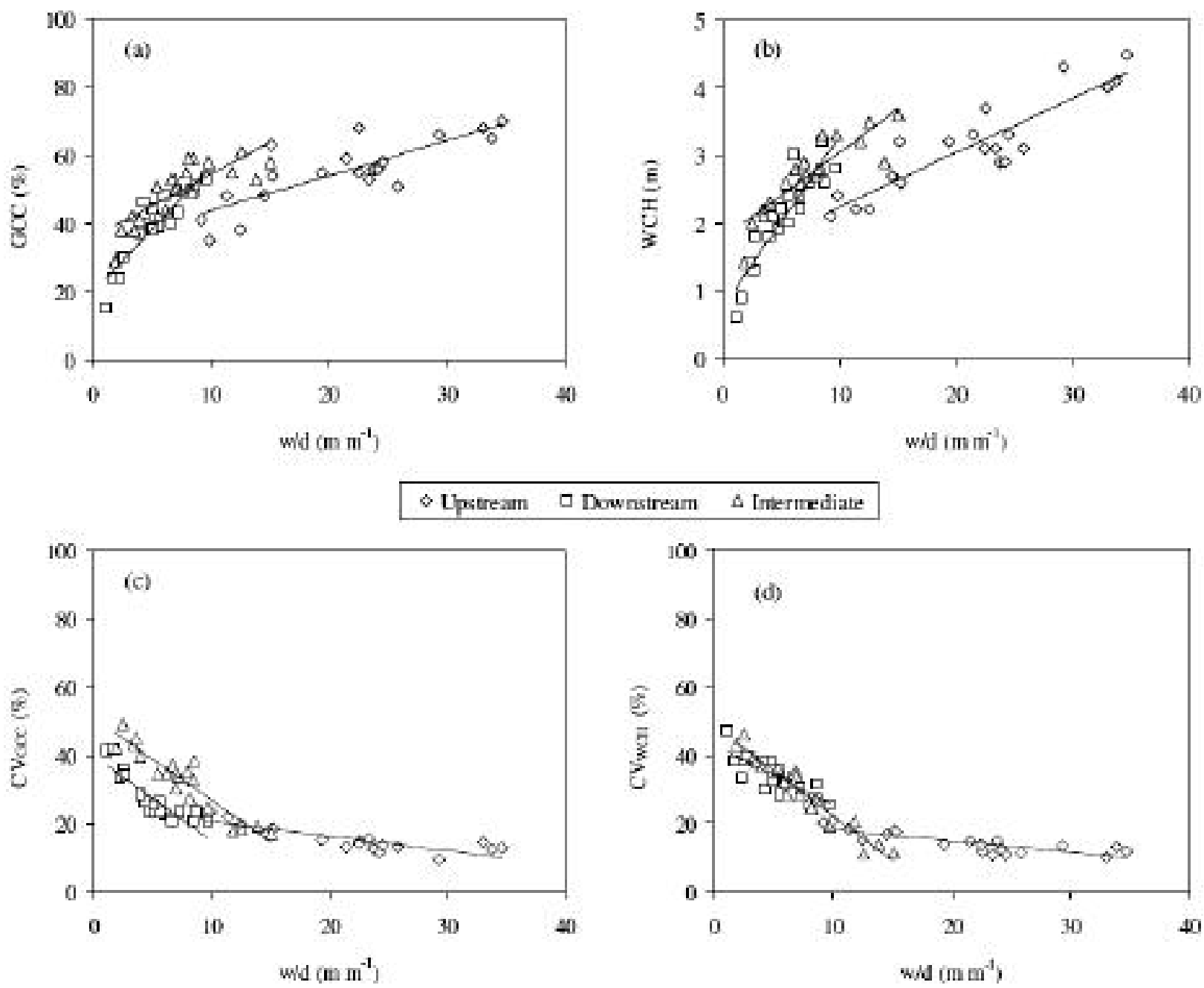

Fig. 6 - a, b, c, and d Relationships between the vegetation synthetic parameters GCC, WCH, $\mathrm{CV}_{\mathrm{GCC}}$ e $\mathrm{CV}_{\mathrm{WCH}}$ and the width:depth ratio (w/d) in upstream, downstream and intermediate transects around the 20 check dams of the study mountain reaches in torrents A, TG, SA and G. 

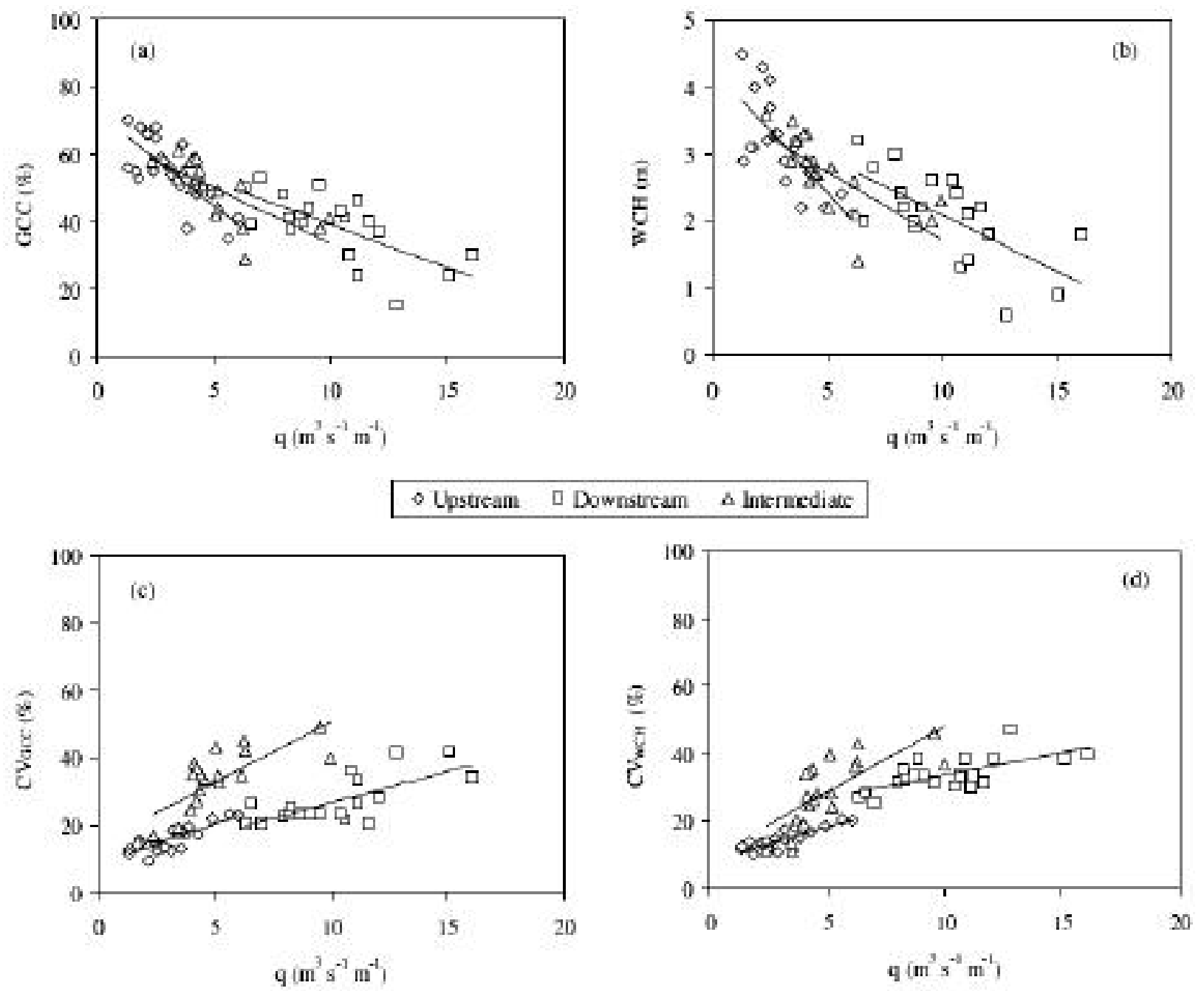

Fig. 7 - a, b, c and d Relationships between the vegetation synthetic parameters GCC, WCH, $\mathrm{CV}_{\mathrm{GCC}}$ e $\mathrm{CV}_{\mathrm{WCH}}$ and the specific discharge (q) in upstream, downstream and intermediate transects around the 20 check dams of the study mountain reaches in torrents A, TG, SA and G.

Overall, the hydrogeomorphological and ecological effects exerted by the control works on river flow, channel and vegetal complexes are well known: the analysis performed confirms on a quantitative approach that in upstream transects the development of riparian vegetation is supported by: i) the higher water retention capacity of the bed material during dry periods because of the greater content of sub-surface fine sediment; ii) the lower mechanical stresses imposed by river flows during wetter periods, which lead to lower extirpation rates and lower mechanical damage to surviving plants; and iii) the greater availability of space within the transect, which allows the establishment of new vegetal complexes. As a result, riparian vegetation is spatially extensive, well-developed (fig. 6a, b and 7a, b) and shows less spatial variability than in downstream and intermediate transects (fig. 6c, d and 7c, d). Because of the naturally steep profile of the study torrents, intermediate sections, located between check dams and less influenced by their presence, tend to be more similar to channels located immediately downstream of check dams than those located upstream. Indeed, the conditions up- stream of check dams can provide such favourable conditions for riparian vegetation development that species richness can exceed than found in intermediate reaches [Bombino 2006].

\section{Conclusions}

Following a wider research activity aimed at assessing the implications of river control works on an riparian ecosystem, this paper contributes to a better comprehension of the ecological response of riparian vegetation to the effects locally induced by hydrogeomorphological processes in proximity of check dams located in mountain reaches of four Calabrian torrents.

The results of the analysis demonstrate clear and relevant modifications, due to the presence of check dams, in the physical properties and vegetation parameters of upstream, downstream and intermediate sites in high-energy, laterally confined locations represented by fiumaras.

The field surveys interpreted through the PCA 
highlighted in all transect groups evident relationships between groups of physical and vegetation properties (WCH, GCC, w/d and \%fines on the one hand and $\mathrm{CV}_{\mathrm{GCC}}, \mathrm{CV}_{\mathrm{WCH}}$ and $\mathrm{q}$ on the other hand); moreover higher associations between groups of vegetation parameters (or their variability along the river cross section) and w/d ratio, specific discharge or fine sediment content have been demonstrated.

Further analysis showed different relationships for groups of transects (upstream, downstream and intermediate), by correlating the coverage and the development of riparian vegetation on one hand and channel morphology (e.g. cross section shape and dimensions, naturally steep profile) or flow hydraulics (e.g. flow velocities and bed shear stresses) on the other hand. Thus the changes in active channel form and specific discharge capacity upstream of check dams surveyed in the study catchments is also accompanied by changes in sediment calibre and size (and therefore in water retention capacity), which offer improved growing conditions for many riparian species. Our results suggest that these changes in environmental conditions above check dam lead to more consistent vegetation development across the active channel and an increase in species richness relative to other transects, but notable increases in vegetation cover and development only arise where the width:depth ratio is substantially enlarged.

Overall we have shown that check dams have far reaching effects on mountain torrent channels, which extend far beyond physical adjustments to the changed hydraulic, morphological and sedimentary conditions. In particular, important and complex changes occur in the extent and development of riparian vegetation as the channels take on new quasi-equilibrium forms.

This research helps to better understand the effects of check dam installation on hydrogeomorphological fluvial processes and their implications on riparian vegetation ecology. Further research activities are needed in order to focus the relevance of each identified physical and ecologic effect and to extend and eventually confirm the research outcomes to other reaches and water courses, where the transferability of the methods utilised can be evaluated.

\section{Acknowledgment}

We thank the anonymous referee for the valuable comments and suggestions, which certainly help to improve the paper.

\section{References}

Bombino G., Tamburino V., Zimbone S.M., Influenza delle briglie sulla vegetazione ripale: il caso-studio di una fiumara calabrese. Rivista di Ingegneria Agraria, 2003, 2, 3-10.

Bombino G., Tamburino V., Zimbone S.M., Assessment of the effects of check-dams on riparian vegetation in the mediterranean environment: a methodological approach and applications. Ecological Engineering, 2006, 27, 134144.

Bombino G., Gurnell A.M., Tamburino V., Zema D.A., Zimbone S.M., A method for assessing channelization effects on riparian vegetation in a Mediterranean environment. River Research and Applications, 2007a, 23, 613-630.

Bombino G., Tamburino V., Zema D.A., Zimbone S.M., Influenza delle briglie sulla vegetazione ripale: implicazioni sulla biodiversità in fiumare calabresi. In: Quaderno di Idronomia Montana, Editoriale BIOS, 2007b, 27(1), Cosenza (Italy).

Bombino G., Gurnell A.M., Tamburino V., Zema D.A., Zimbone S.M., Sediment size variation in torrents with check-dams: effects on riparian vegetation. Ecological Engineering, 2008a, 32, 166-177.

Bombino G., Tamburino V., Zema D.A., Zimbone S.M., Gurnell A.M., Valutazione degli effetti delle briglie sulla vegetazione ripale: analisi di quattro casi-studio calabresi. L'Acqua, 2008b, 4, 17-25.

Bombino G., Gurnell A.M., Tamburino V., Zema D.A., Zimbone S.M., Adjustments in channel form, sediment calibre and vegetation around check dams in the headwater reaches of mountain torrents, Calabria, Italy. Earth Surface Processes and Landforms, 2009a, 34, 10111021.

Bombino G., Tamburino V., Zema D.A., Zimbone S.M., Influenza della morfologia dell'alveo sulla vegetazione ripale in tronchi montani di fiumare sistemati con briglie. Proceeedings of the IX National Congresso of the Italian Association of Agricultural Engineering, 2009b, Ischia Porto (Naples, Italy), 12-16 settembre.

Braun-Blanquet J., Plant Sociology - The Study of Plant Communities. McGraw-Hill, 1932 (English translation 1965), New York.

Braun-Blanquet J., Pflanzensoziologie. Springer, 1964, Wien.

Corenblit D., Tabacchi E., Steiger J., Gurnell A.M., Reciprocal interactions and adjustments between fluvial landforms and vegetation dynamics: a review of complementary approaches. Earth Science Reviews, 2007, 84, 5686.

Gregory K.J., D.E. Walling. Drainage Basin Form and Process. 1973. New York, Halsted Press.

Gurnell A.M., Vegetation along river corridors: hydrogeomorphological interactions. In Gurnell, A.M. and Petts, G.E. (eds.), Changing River Channels. Wiley, 1995, Chichester, 237-260.

Gurnell A.M., Petts G.E., Island-dominated landscapes of large floodplain rivers, a European perspective. Freshwater Biology, 2002, 47, 581-600.

Gurnell A.M., Petts G.E., Trees as riparian engineers: the Tagliamento River, Italy. Earth Surface Processes and Landforms, 2006, 31, 1558-1574.

Hupp C.R., Rinaldi M., Riparian vegetation patterns in relation to fluvial landforms and channel evolution along selected rivers of Tuscany (Central Italy). Annals of the Association of American Geographers, 2007, 97, 12-30.

Lenzi M.A., Stream bed stabilization using boulder check dams that mimic step-pool morphology features in Northern Italy. Geomorphology, 2002, 45, 243-260. 
Leopold L.B., Wolman M.G., Miller J.P., Fluvial Processes in Geomorphology. W.H. Freeman and Company, 1964, San Francisco, CA., 522 pp.

Malkinson D., Wittenberg L., Scaling the effects of riparian vegetation on cross-sectional characteristics of ephemeral mountain streams-a case study of Nahal Oren, Mt Carmel, Israel. Catena, 2007, 69, 103-110.

Nakamura F., Swanson F.J., Wondsell S.M., Disturbance regimes of stream and riparian systems - a disturbancecascade perspective. Hydrological Processes, 2000, 14, 2849-2860

Pearson K., On lines an planes of closest fit to a system of points in space. Philosophical Magazine, 1901, 2(6), 559-572.

Petts G.E., Gurnell A.M., Dams and geomorphology: research progress and new directions. Geomorphology, 2005, 71, 27-47.

Richards K.S., Rivers, Form and Processes in Alluvial Channels, 1982, Methuen, London, 358 pp.

Shafroth P.B., Stromberg J.C., Patten D.T., Riparian vegetation response to altered disturbance and stress regimes. Ecological Applications, 2002, 12, 107-123.

Sharma S., Applied multivariate techniques. John Wiley \& Sons, 1996, New York.

Versace P., Ferrari E., Gabriele S., Rossi F., Valutazione delle piene in Calabria. CNR-GNDCI, LINEA 1, CNRIRPI, Geodata, 1989, Cosenza (Italy), 30.

\section{SUMMARY}

The complex hydrogeomorphological processes within the active channel of rivers strongly influence riparian vegetation development and organization, particularly in mountain streams where such process- es can be remarkably impacted by engineering control works.

In four mountain reaches of Calabrian fiumaras we analyze, through previously arranged methods (integrated by a multivariate statistic analysis), the relationships among hydrogeomorphological river characteristics and structure and the development of riparian vegetation within the active channel in transects located in proximity of check dams and in less disturbed sites.

The results of this study demonstrate clear and relevant contrasts, due to the presence of check dams, in the physical and vegetation properties of upstream, downstream and intermediate sites around check dams.

The multivariate statistical approach through the Principal Component Analysis (PCA) highlighted evident relationships in all transects between groups of physical and vegetation properties. The regression analysis performed between the vegetation properties and the width:depth ratio or the specific discharge showed very different relationships between groups of transects, due to evident changes in channel morphology and in flow regime locally induced by check dams.

Overall we have shown that check dams have far reaching effects in the extent and development of riparian vegetation of mountain torrent reaches, which extend far beyond physical adjustments to changed morphological, hydraulic and sedimentary conditions.

Keywords: fiumara, check dam, riparian vegetation, hydrogeomorphology, Principal Component Analysis. 
004_Bombino(575)_37 1-12-2010 9:51 Pagina 48 